\title{
Fertility of Male Syrian Hamsters Paired with One, Two and Four Proestrous Females Each
}

\author{
Takao YAMAGUCHI, Toru R. SAITO*, Ryoji HOKAO**, Kohji MATSUO, \\ Yasumasa WAKAFUJI**, and Kazuaki W. TAKAHASHI*
}

\section{J.A.C.Inc, Dai-ichi Inari Building, 2-20-13 Aobadai, Meguro-ku, Tokyo 153, 'Department of Laboratory Animal Science, Nippon Veterinary and Animal Science University, 1-7-1 Kyonan-cho, Musashino-shi, Tokyo 180, and ${ }^{* *}$ Tsuchiura Laboratories, Imamichi Institute for Animal Reproduction, 1103 Fukaya, Dejima-mura, Niihari-gun, Ibaraki 300-01, Japan}

(Received 27 October 1992/Accepted 25 December 1992)

\begin{abstract}
In order to improve the productivity of Syrian hamsters, we investigated whether a male could impregnate overnight more than one proestrous female. Twenty-one males and 49 females aged 8 to 10 weeks were used in this experiment. The mating systems were as follows : one male was paired with one female, one male was paired with two females, and one male was paired with four females. Six out of 7,7 of 14 and 4 of 28 females became pregnant and gave birth under these three systems, respectively. We conclude that it is possible for a male to impregnate overnight about one female under the above mating systems.—KEY WORDS : mating system, pregnancy, Syrian hamster
\end{abstract}

\section{シリアンハムスターの雄 1 匹に対する発情雌 $1 ， 2$ および 4 匹交配時の繁殖成績}

山口孝雄・斎藤 徹*・外尾亮治**・松尾紘二 若藤 靖 匡 ${ }^{* *} \cdot$ 高橋和 明*

\footnotetext{
株式会社ジェー・エー・シー

*日本獸医畜産大学実験動物学教室

**財団法人動物繁殖研究所
}

実験動物の供給施設においては実験動物の繁殖を行 う際，通常，雄雌 1 対 1 およびハーレム方式がとられ ている。数少ない雄が多数の雌を妊娠・出産させるこ とは, 生産効率の面から考えて非常に意義深いものと 思われる。

若藤（1985）ら［2］は雄ラット1匹に対して発情 雌を $1 ， 2 ， 3$ および 5 匹交配時の妊娠率は，それぞ れ 100，90，87 および $60 \%$ あっったと報告している。

一方, 雄シリアンハムスターの交尾能力は, ラット に比較して活発である $[3,6]$ 。すなわち，一定時間内
の射精回数においてシリアンハムスターは，ラットに 比較して多いことが特徴とされている。

そこで, 今回我々は 1 匹の雄のシリアンハムスター が, ラットと同様に多数の雌を妊娠, 出産させること が可能であるか検討した。

供試動物：(財) 日本生物科学研究所より購入した生 後 4 週秢の GN 系シリアンハムスター70（雄 21 , 雌 49）匹を用いた。

飼育環境：動物は温度 $24 \pm 2{ }^{\circ} \mathrm{C}$, 湿度 $55 \pm 10 \%$, 換気回数 1 時間 12 回（オールフレッシュエアー方 


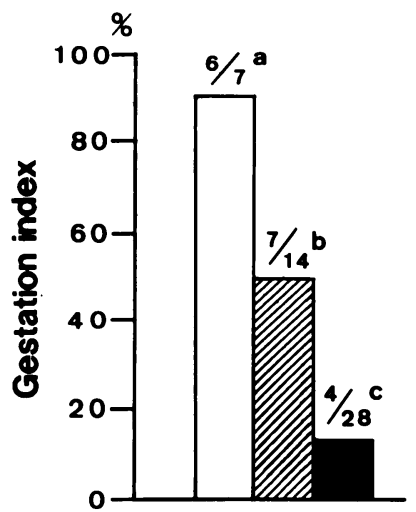

Fig. 1. Reproductive activities when one, two and four female Syrian hamsters were paired with one male $\square: 1$ male to 1 female $\mathbb{E}: 1$ male to 2 females $\square: 1$ male to 4 females $\mathrm{P}<0.05 \mathrm{~b}$ vs. c $\mathrm{P}<0.001$ a vs. $\mathrm{c}$

式), 人工照明 1 日 14 時間 (午前 5 時点灯, 午後 7 時 消灯）に設定された動物室にて，アルミ製弁当箱型 ケージ $(26 \mathrm{~W} \times 40 \mathrm{D} \times 20 \mathrm{Hcm})$ に床敷としてチップ を入れ 4 〜 匹ずつ収容された。

飼料, 水: 固型飼料（オリエンタル酵母工業株式会 社製 NMF）を飽食させ，水を絶やさないようにし た。

交配条件：雄 1 匹に対し発情雌 1 匹の組合せ，雌 2 匹の組合せおよび婎 4 匹の組合せ, それぞれ 7 組の 3 群を作出した。

交配方法：雌雄とも生後 8１0 週跲より交配実験 に用いた。雌は交配実験に先立ち, 臸分泌物性状の観 察および胵垢の採取を行い，4 日性周期を連続して 3 回以上繰り返した後, 発情前期の胵垢像 $[4,5]$ を示 した動物 (以下, 発情雌) を選び, 午後 7 時から翌日 の午前 9 時まで同居交配した。交配にはアルミ製の弁 当箱型のゲージを用い, そのサイズは雄雌の組合せに よる動物数の違いを考虑し，下記の通りとした。雄雌 $1: 115 \mathrm{~W} \times 23 \mathrm{D} \times 20 \mathrm{H}, 1: 221 \mathrm{~W} \times 33 \mathrm{D} \times 20$ $\mathrm{H}, 1: 431 \mathrm{~W} \times 46 \mathrm{D} \times 20 \mathrm{Hcm}$ 。なお, 交配終了時 に雌は胵栓および精子を確認（妊娠 0 日）の後, 個別 飼育され，分婏前日まで毎日臸垢の採取と観察を行っ た。

妊娠判定：出産動物については産子数を調べた。な お，分婏の幑候がみられない出産予定日を過ぎた個体 については, 解剖し着床痕の有無を調べた。

統計処理：Fisher's exact probability test [1] を 用いた。
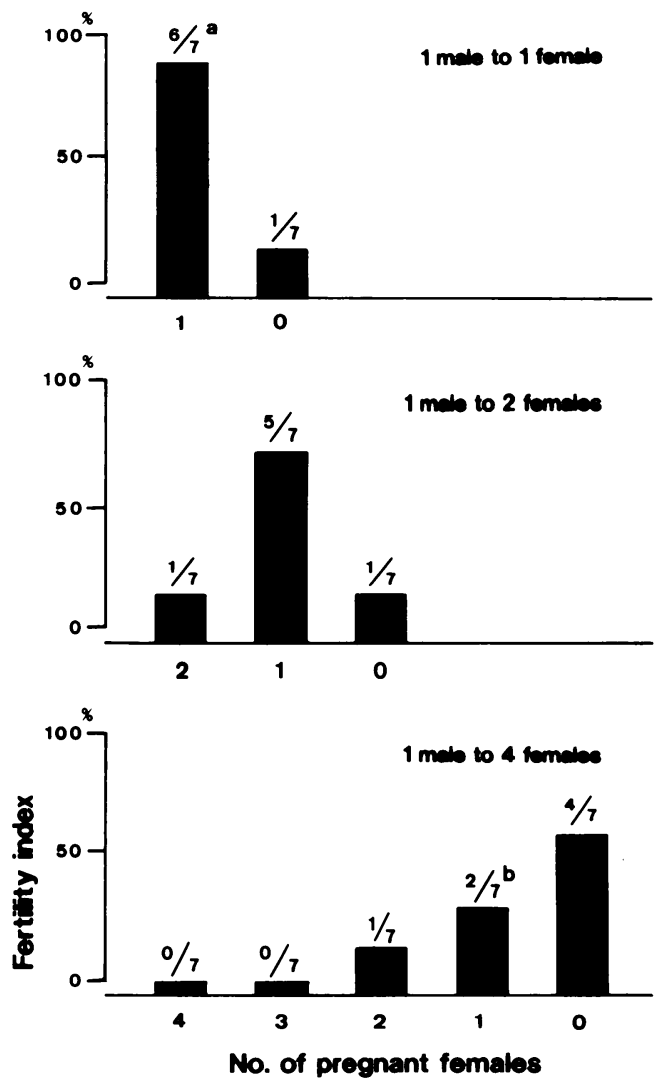

Fig. 2. Reproductive activity of male Syrian hamsters paired with one, two and four females each $\mathrm{P}<0.05$ a vs. $\mathrm{b}$

Fig. 1 に各群におけるそれぞれの雌の出産率にう いて示した。

雄 1 匹に対する発情雌 1 匹交配群の出産率は, 6/7 例 $(85.7 \%$ ) であった。出産に至らなかった 1 例 (14.3\%) には, 精子が認められず4 日周期を反復し た。

雄 1 匹に対する発情雌 2 匹交配群の出産率は, 7/14 例 $(50.0 \%)$ であった。出産に至らなかった 7 例の内 訳は以下の如くであった。すなわち, 流産が 2 例 $(14.3 \%)$, 偽妊娠が 1 例 $(7.1 \%)$ および 4 日周期を 反復した個体が 3 例 (21.4\%) それぞれ钼察された。 なお，精子が認められなかった 1 例 $(7.1 \%)$ は 4 日 周期を反復した。

雄 1 匹に対する発情䧳 4 匹交配群の出産率は, 4/28 例 $(14.3 \%)$ であった。出産に至らなかった 24 例 (85.7\%) の内訳は以下の如くであった。すなわち, 偽妊娠が 1 例 (3.6\%) および4 日周期を反復した個 
体が 3 例 (10.7\%) それぞれ観察された。残りの 20 例(71.4\%) には精子が認められず，その内 1 例 （3.6\%）が偽妊娠を示した。

上記の如く，出産率においては雄 1 匹に対する発情 雌 4 匹交配群が発情雌 1 匹交配群（P<0.001）およ び発情雌 2 匹交配群（P<0.05）に比較して有意に低 い值を示した。

Fig. 2 に各群の雄の妊孕率を示した。

雄 1 匹に対する発情雌 1 匹交配群の妊孕率は，6/7 例 $(85.7 \%)$ であった。

雄 1 匹に対する発情雌 2 匹交配群の妊孕率は，2 2 匹 の雌を出産させた雄の割合は $1 / 7$ 例 $(14.3 \%)$ であ ク,どちらか 1 匹のみを出産させた割合は $5 / 7$ 例 (71.4\%) であった。残り 1 例 (14.3\%) は 1 匹の雌 も出産させることが出来なかった。

雄 1 匹に対する発情雌 4 匹交配群の妊孕率は，4 4 匹 全て，または 3 匹の雌を出産させた雄は認められず, 4 匹中 2 匹の雌を出産させた雄の割合は $1 / 7$ 例 (14.3\%)，4匹中 1 匹の雌を出産させた雄が 2 例 (28.6\%) および 1 匹の雌も出産させなかった雄が 4 例 (57.1\%) それぞれ観察された。

上記の如く，各群における 1 匹のみの雌を出産させ た雄の割合は, 発情雌 4 匹交配群 $(\mathrm{P}<0.05)$ が発情 雌 1 匹交配群に比較し有意に低い值を示した。

以上の如く，生産効率の向上を目的に各群 7 匹の雄 を用いて，雄雌 $1 ： 1 ， 1 ： 2$ および $1 ： 4$ の組合せ にて交配を実施した結果，それぞれ $6 ， 7$ および 4 匹 の妊娠・出産ハムスターが得られた。すなわち，1匹 の雄シリアンハムスターが 1 日に妊娠させうる雌の数 は概ね 1 匹に過ぎないものと思われる。

雄雌 $1 ： 2$ の交配群において, 成績に述べた如く 14 例中 13 例の雌の腟内に精子が認められたことよ ク，必ずしも特定の雌のみとの交尾が行われたのでは ないことが窥われる。それにもかかわらず，妊娠・出 産に至った割合は $7 / 13$ 例と低率であった。その理由 として，妊娠成立に十分な射精回数（精子数）および 交尾回数（交尾刺激）が得られなかったものと考えら れる。次に，雄雌 1：4の交配群についてみると，28 例中 20 例の雌の臸内に精子が認められず，その内 19 例が 4 日周期を画いていることより，この交配群にお いては雄雌 1：2の交配群とは異なり，雄の交尾行動
そのものが何らかの原因により抑制されているものと 思われる。これらの点を明らかにするためには，雄の 交尾行動および個々の雌が受けた交尾行動（マウン ト，イントロミッション，射精）を詳細に観察する必 要があるものと考えられる。

最後に，若藤ら［2］のラットの成績と比較してみ ると，明らかに顕著な差異がみられる。ラットの場 合, 雄雌 1 ：5の交配時において雄の妊孕率は 60\% であるのに对して, シリアンハムスターの雄雌 $1 ： 4$ の交配群のそれは $14 \%$ と低率であった。この両者の 差異は何に起因しているのか, 今後の検討課題とした い。

\section{要 約}

シリアンハムスターの生産効率の向上を計る方法を 探るため，まず 1 匹の雄が何匹の発情雌を 1 晚の同居 交配により妊娠させることが可能であるかを検討し た。生後 8〜10 週粭の雄 21 匹を用いて, 雄雌 1 ： 1，1：2 および 1：4の交配群における雄の妊孕能 について調べた結果, 各々 $6 / 7,7 / 14$ および $4 / 28$ 例 の妊娠・出産動物が得られた。したがって，シリアン 八ムスターの交配においては，雄雌 $1 ： 2$ および 1 ： 4 の交配方法を採用しても生産性の高率化には結びつ かないものと思われた。

本論文に対し、ご指導, 御鞭撻を賜った東北大学医学部教授 信水利馬博士に深謝する。また，本研究の遂行にあたりご助言 を頂いた株式会社ジェー・エー・シー前社長北村 昭ならひに株 式会社ケー・エー・シー常務取締役河邊行廣の両氏に感謝する。

\section{文献}

[1] Gad, S. C. and Weil, C. S. (1982). In Principles and Methods of Toxicology, pp, 291-292. Hayes, A. W. (edit.), Raven Press, New York.

［2］若藤靖匡・高倉元史・外尾亮治・津江本由美子・高橋和明・ 今道友則 (1985)。家畜繁殖誌, 31，110-114.

（3］山口孝雄・小出正雄・斎藤 徽 (1988). 実験動物，37， 485-488

４４］山口孝雄-小出正雄・高橋和明（1987）。実験動物技術, $22,39-47$

［5］山口孝雄・小出正雄・高橋和明 (1988)。実験動物技術, 23, 26-30.

［6］山口孝雄・斎藤 徽 (1987). 実験動物，36，209-212。 